\title{
Design of the Administrative Building of Kuhsar City under a Sustainable Architecture Concept Approach
}

\author{
Hamid Reza Mafakheri \\ Department of Architecture, \\ Hidaj branch, Islamic Azad \\ University, \\ Hidaj, Iran.
}

\author{
Amir Hosin Hejazi \\ Department of Architecture, \\ Abhar branch, Islamic Azad \\ University, \\ Abhar, Iran.
}

\author{
Mehran Dashti \\ Department of Architecture, \\ Hidaj branch, Islamic Azad \\ University, \\ Hidaj, Iran.
}

\begin{abstract}
This study investigates a sustainable approach in the design of the administrative building of the municipality and Islamic council of Kuhsar city, Iran. The initial design is inspired by a flower bud and the various stages of the design are described using actual images, 2-D plans and 3-D models. An extra focus is given to sustainable elements. Overall the design aims to deliver an energy sufficient yet aesthetically pleasing building.
\end{abstract}

Keywords-Sustainable architecture; city council; municipality; building; energy retention; administrative

\section{INTRODUCTION}

In most countries, experts try to formulate urban controlling rules, building rules and environmental ranking systems to promote sustainable development [1]. In the early 21 th century, shortage of natural resources, population growth and concerns about pollution obliged cities to review environmental plans and determine goals for the future. Issues such as greenhouse gas, using water, urban waste, recycle, land use and environment quality are considered in this process [2]. Sustainable architecture is the manifestation of sustainable development in construction. In sustainable architecture, buildings are not just adapted regarding the climatic conditions of the region, but establish a mutual relationship with it [5]. The goal of design of such buildings is the reduction of damage on environment, energy resources and nature [4].

The important point of this paper is the sustainable architecture approach to environmental issues. However, it is difficult to separate this issue from other economic, cultural and social aspects. Further, although current critical results are identified well, most of presented solutions are inefficient. Considering the importance of fossil energy consumption, pollution and climatic change, the full re-evaluation and possible reform of buildings under construction emerges as a necessity. Sustainable architecture in Iran, in residential and non-residential areas, is not that much followed and existing buildings, especially public establishments, are mainly energy consumers. To respond to the climatic needs of each region in Iran, traditional architecture should also be considered. This study aims to investigate sustainable environmental and sustainable architecture theories in an attempt to help in policy definition.

\section{FAMOUS EXAMPLES OF SUSTAINABLE BUILDINGS}

\section{A. HSBC building in Shangai}

The HSBC building in Shanghai is designed under the unique styles of Norman Foster. It stands $180 \mathrm{~m}$ above ground with four basements levels. There are 47 floors with a rectangle plan approximately $54 * 70 \mathrm{~m}$. The middle atrium is $52 \mathrm{~m}$. Lifts stop at certain floors only and floors are connected via escalators. The structure of the building is visible mainly due to maintenance principles. Sea water is used as an initial cooler for the ventilation system, as well as for the washing system and WC. To increase the lighting in central space solar mirrors following sun movements are used [3].

\section{B. Guggenheim Museum}

The museum has a statue-oriented form of simple design. It has an approximate height of $250 \mathrm{~m}$ and dome ceiling with a 12-angle spider web skylight. A central inverse cone atrium is saturated with natural light.

\section{Swiss Re building}

Swiss Re building has 41 floors and an overall area of $76400 \mathrm{~m}^{2}$. In this tower, some ideas a new rapport between nature and the work place, is its energy-conscious enclosure resolving walls and roof of a continuous triangulated skin. The tower has a radial plan with a circular perimeter. From halfprofile, this is widened to top and then its width is reduced and it is minimized at the end.

\section{CASE STUDY}

\section{A. Location}

Kuhsar city is located in Iran (Figure 1). Due to the limited extension of this city, the existing height difference has no effect on weather conditions. The highest height in Kuhsar city is observed in the north end of the city with a height of $1640 \mathrm{~m}$ and lowest height is found south west with a height of $1310 \mathrm{~m}$. The center of Kuhsar city is located at a height of $1450 \mathrm{~m}$ from sea level. Based on the topography conditions of the region, 
Savojbolagh town can be divided into mountainous, foothills and plain area. About $25 \%$ of town area is mountainous. The foothills area is in the southern range of the Taleghan mountain. The average temperature there is higher compared to the mountainous area. Three factors play an important role also: the Kavir plain, the Alborz mountains and the humid west winds. According to long-term statistics (1985-2005), the annual average of air temperature (dry air) is $15.8^{\circ} \mathrm{C}$. July and August with 28.4 and $28.2^{\circ} \mathrm{C}$ have the highest and January and February with 2.2 and $4.4{ }^{\circ} \mathrm{C}$, have the lowest temperature.

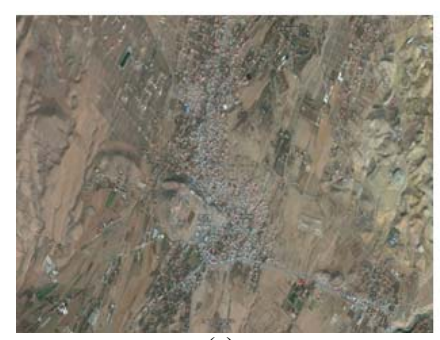

(a)

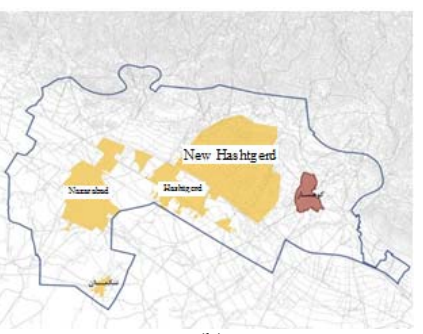

(b)
Fig. 1. a) Aerial photo of Kuhsar city (b) The map of Savojbolah and Kuhsar city

Generally, the selection of building location depends upon some factors as natural condition of earth, the need to private spaces, reduced noise, wind and sun. Southern direction is usually considered optimum as it can result to achieving highest solar energy in winter and lowest in Summer. The total annual rainfall (2007) in the Synoptic station of Karaj, the closest station to Kuhsar town, is $393.5 \mathrm{~mm}$. Maximum relative humidity in 2007 was $91 \%$ and minimum relative humidity in the same year was $15 \%$. The dominant wind in the region is northwestern and its geographical direction is $315^{\circ}$ between north and West. The historical review of earthquake shows a relatively high risk [6]. Figure 2 show the master plan of Kuhsar city and its border.

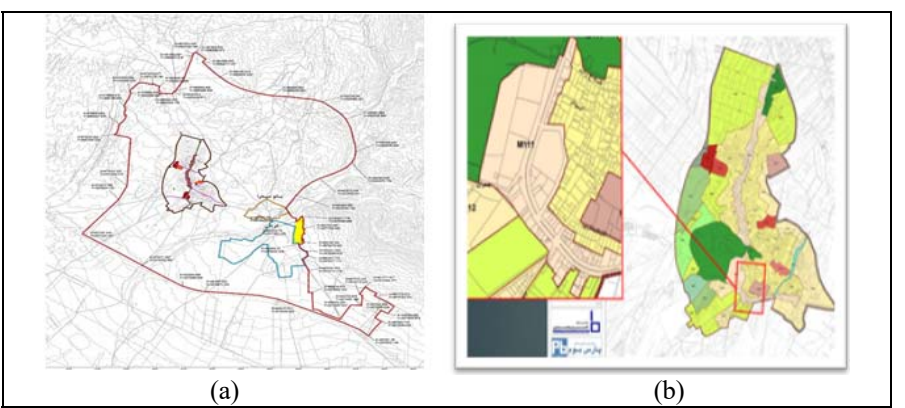

Fig. 2. a) The city border map of Kuhsar b) Master plan of Kuhsar city

The selected site is located in a mixed-use zone of Kuhsar city (commercial, administrative , service and residential) with a density of $240 \%$. Most offices (electricity offices, health houses, urban services etc.) are located in this area and there is a suitable access via two streets. A third road is under construction in close proximity. The site is located at a height of $1400 \mathrm{~m}$ and in a distance of $12 \mathrm{~km}$ from the Karaj-Qazvin highway (Figure 3). Figure 4 shows some images of the site.

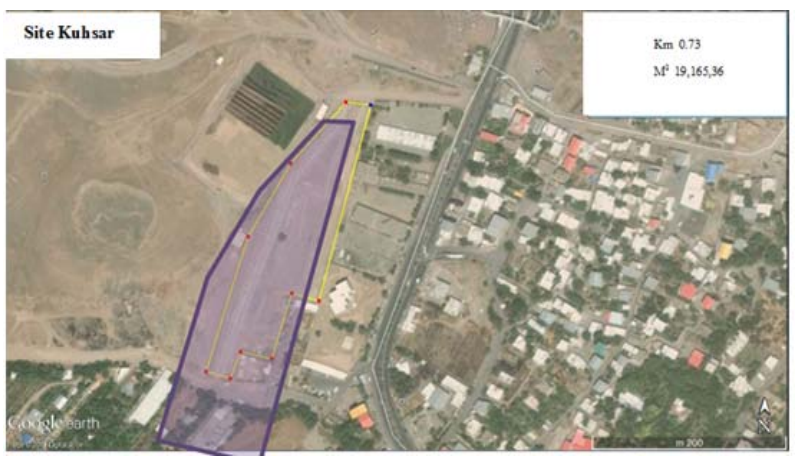

Fig. 3. Aerial photo of the site

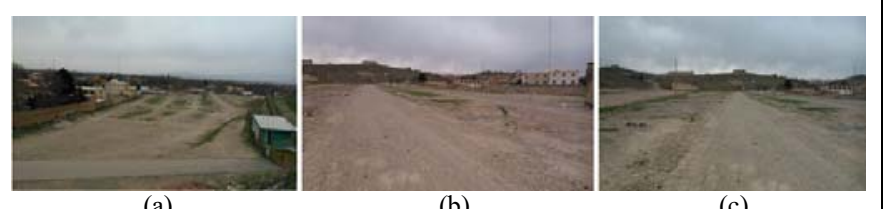

(a)

Fig. 4. (a): north to south site (b): south to north site(c): south to north site

\section{B. Idea and concept}

The concept of the project is based on a flower bud as shown in Figure 5. Several instants from the design trend are shown in Figure 6. The designs for each floor are shown in Figure 7
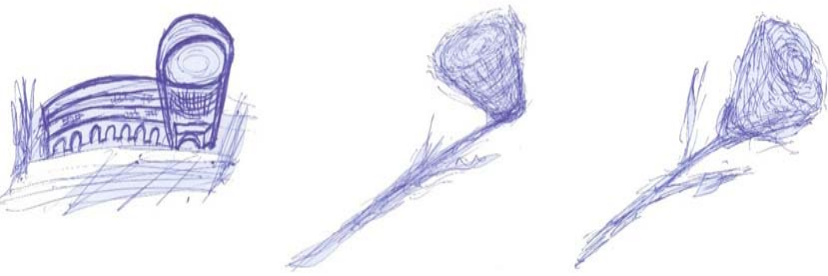

Fig. 5. Project concept
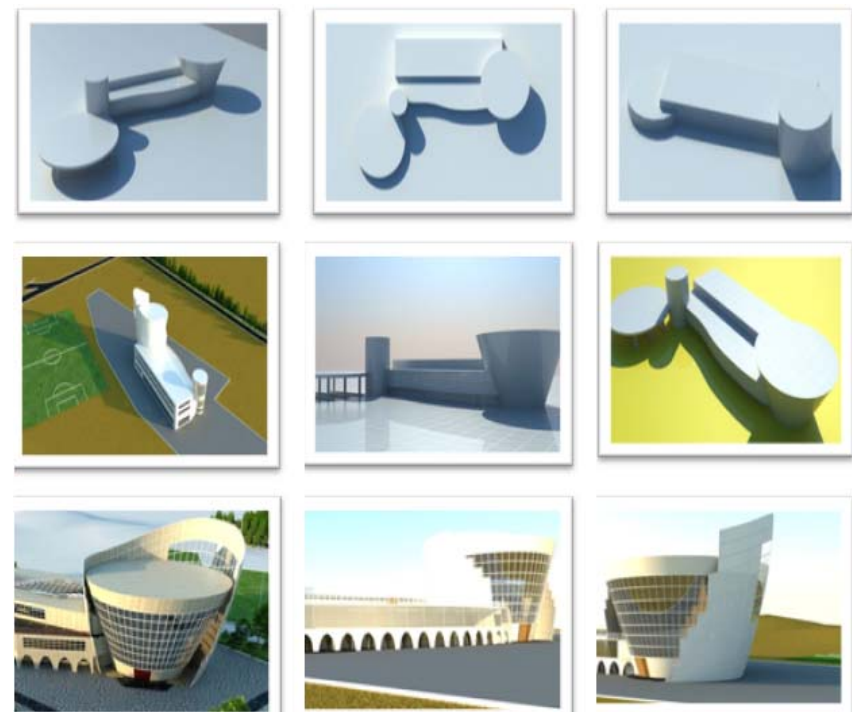

Fig. 6. Design trend of the project 

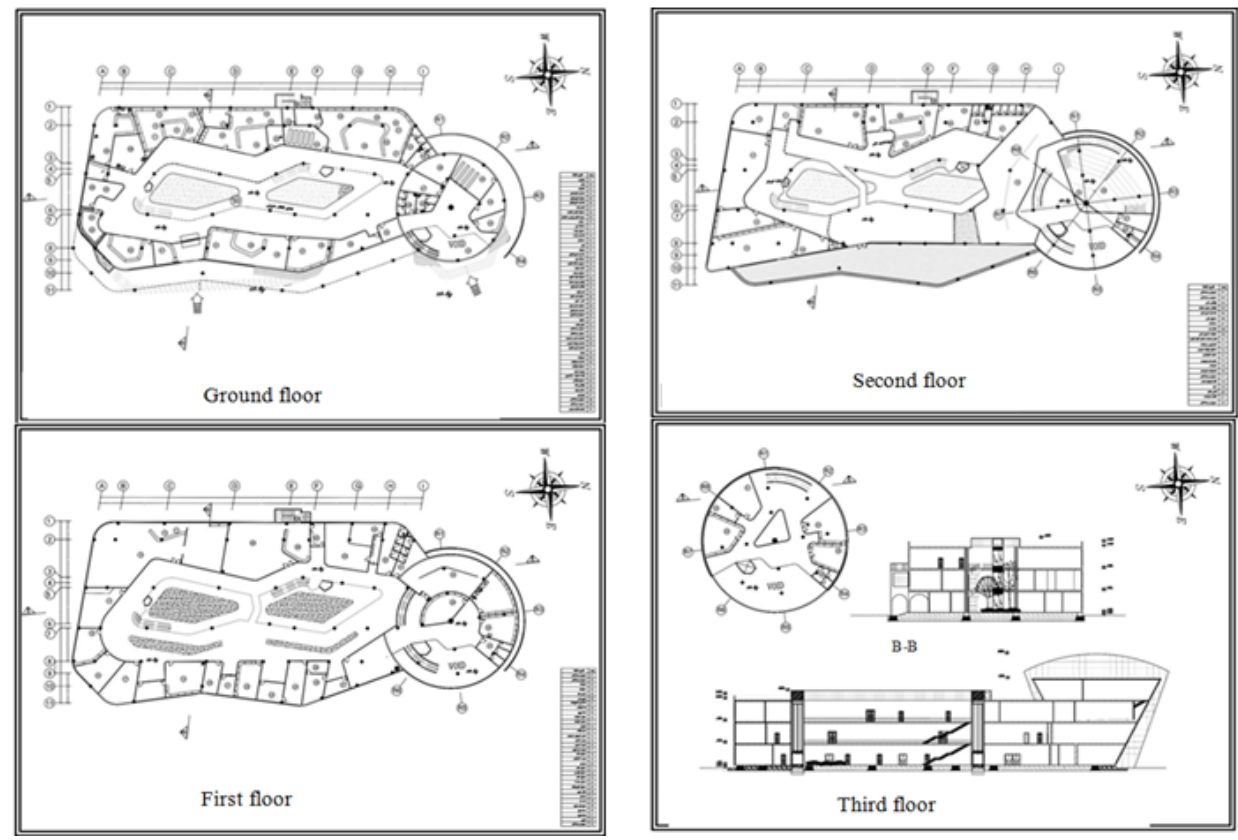

Fig. 7. Plans from the project

\section{Using a central atrium}

Such intermediate spaces, atriums, are used for natural lighting, internal comfort, mild and spatial sub-climate. The skylights may be of different dimensions and forms and have glass-covered ceiling and lateral walls with various materials, usually different from plain building materials. An atrium is suitable to absorb solar energy and facilitate heat storage (in winter) and air circulation (in summer) (Figure 8).

\section{Using external louvers}

The highest solar energy absorption in summer is done via windows. To do this, external vertical louvers can be installed in the east and south of the building, and horizontal louvers in the west (Figure 9).

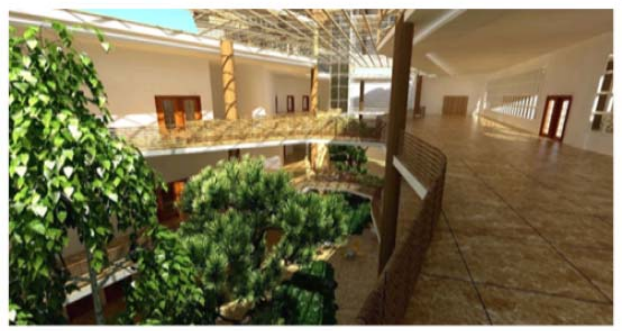

Fig. 8. Image of the central atrium

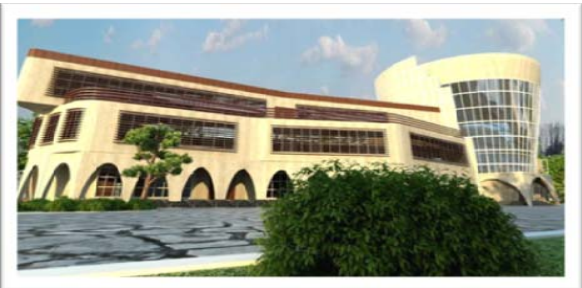

Fig. 9. Image of external louvers

\section{E. Using external skin in city council for sustainable architecture}

Creating skin as a secondary will increase the shading of the building and thus reduce the absorbed heat. In the winter it will help protect the building from the cold North West winds (Figures 10 and 11).

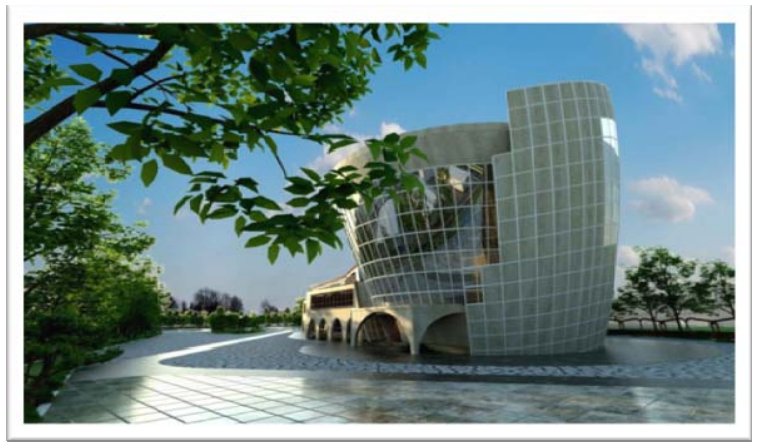

Fig. 10. The external wall

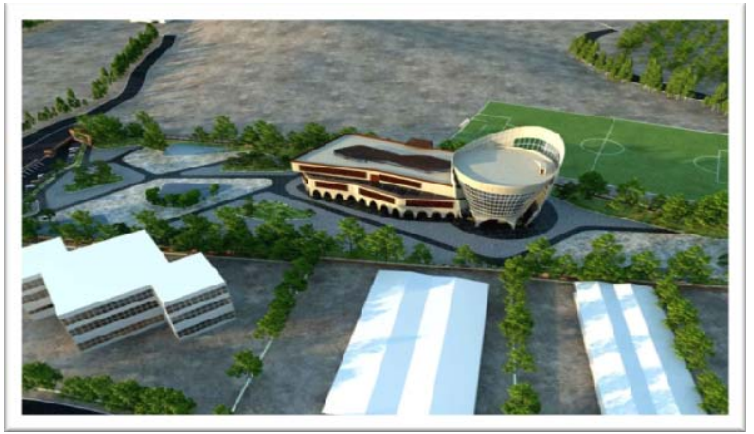

Fig. 11. Overview of the building 


\section{F. Looking over the city}

The terrace overlooking the city serves two additional purposes as it will allow employees to gaze upon the city and also provide a feeling of reassurance to the citizens (Figure 12).

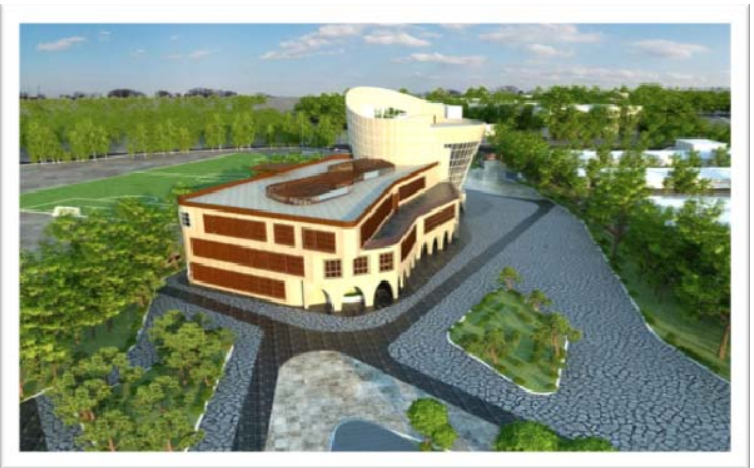

Fig. 12. Looking over the city

\section{G. Application of urban matrix in site design}

Finally, the main streets of the city have been incorporated in the design of the building providing easy access and pleasant walking routes along fountains and green areas (Figures 13 and 14).

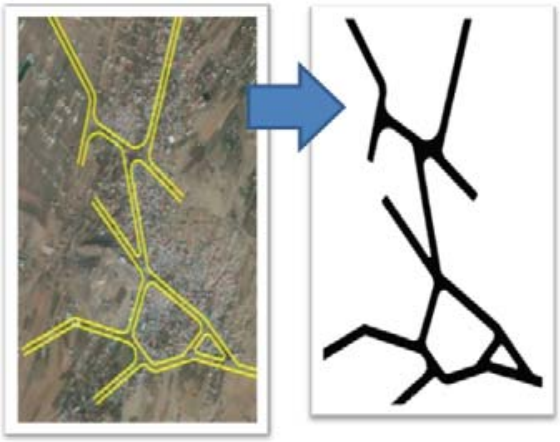

Fig. 13. Urban matrix extraction trend from city passages

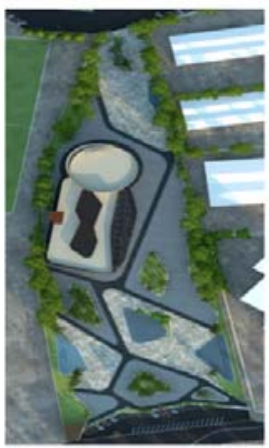

Fig. 14. Figure 14-Urban matrix image in site design

\section{CONCLUSION}

This paper presents the design of the municipality and Islamic council building of Kuhsar city under a sustainable approach. The site's location is also presented and a walkthrough of the design is given, focusing on the most important, and unique, aspects. Actual images as well as 2-D designs and 3-D models are given. The building was inspired by a flower bud and certain elements of sustainable architecture have been implemented (a central atrium, external louvers, a second skin external wall). This design aims to deliver a practical, energy saving and aesthetically pleasing building.

\section{References}

[1] A. Rezvan, "Sustainable development", Architect News Iran, 2012

[2] S. E. Sayadi, S. M. Mahdavi, "Sustainable architecture", Journal of Architecture and Urbanization in Iran, Vol. 20, No. 68.

[3] M. Golabchi, The investigation of works of Norman Foster. Tehran University publication. 2010.

[4] Y. Gorji, Mahlabani, A. Yaran, Solutions of sustainable architecture of Gilan with comparison with Japan architecture. Fine arts journal. 41, 2010.

[5] M. Mahmoudi, The development of housing consistent with sustainable development. Tehran University publications. Spring. 2013.

[6] Consulting engineers studies of Spadana. P. 20, 2009. 